\title{
A TRADUÇÃO JURAMENTADA DE DOCUMENTOS SUÍCOS: RESULTADOS PARCIAIS EM TORNO DOS TERMOS ESTUDADOS
}

\author{
Maria Emilia Pereira Chanut
}

RESUMO: Os termos legais e/ou jurídicos presentes em documentos oficiais, registros e certidões civis têm como principal especificidade o fato de fazerem referência a sistemas legais cujas lógicas de pensamentos estão ancorados numa cultura jurídica bem particular. Os termos empregados para designar os títulos de pessoas, funções, instituições, departamentos, serviços, leis etc, podem apresentar uma equivalência morfológica terrivelmente enganosa, pois adquirem significados ou usos diferentes em países distintos que falam a mesma língua, como no caso de países francófonos como a França e a Suíça francesa. Nosso estudo, apoiado num corpus de traduções juramentadas, expõe uma abordagem comparativa/ terminológica bilíngue (português do Brasil/francês da França), problematizada por particularidades do francês da Suíça.

PALAVRAS-CHAVE: francês da França; francês da Suíça; tradução juramentada; terminologia.

RÉSUMÉ: Les termes légaux et/ou juridiques présents dans des documents officiels, registres et actes civils ont une caractéristique bien singulière, à savoir qu'ils portent sur des systèmes légaux dont les logiques du raisonnement renvoient à une culture juridique très particulière. Les termes employés pour désigner les titres, fonctions, institutions, départements, services, lois, etc., peuvent présenter une équivalence morphologique terriblement dangereuse car ils acquièrent un sens ou 
emploi différent dans des pays distincts parlant la même langue tels que les pays francophones comme la France et la Suisse romande.

Notre étude, portant sur un corpus de traductions assermentées, expose une approche comparative/ terminologique bilingue (portugais du Brésil/français de France), dont les difficultés sont intensifiées par des particularités du français de Suisse.

MOTS-CLÉ: français de France; français de Suisse; traduction assermentée; terminologia.

\section{Introdução}

O propósito deste artigo é divulgar os resultados parciais relativos a uma pesquisa sobre a tradução juramentada de documentos suiços em língua francesa, visto que os termos estudados apresentam usos diferenciados na França. Além de alguns exemplos puramente ilustrativos, o estudo de caso aqui relatado é parte integrante de uma pesquisa mais abrangente, que propõe paralelamente uma reflexão teórica sobre a "equivalência funcional" .

Nosso estudo expõe uma abordagem terminológica bilingue (português do Brasil/francês da França), problematizada por particularidades do francês da Suíça.

Tais particularidades se refletem diretamente no uso da língua, portanto, o que é mais preocupante é que tais termos podem, algumas vezes, indicar semelhanças terrivelmente enganosas para um tradutor juramentado. Há muitos termos cujos significantes

\footnotetext{
Para um esclarecimento maior sobre a questão da "fidelidade" e da "equivalência funcional" em tradução juramentada, remetemos ao artigo publicado na revista da "Tradução e Comunicação", n 17, da Unibero: “A questão da equivalência funcional em tradução juramentada: o caso do francês da Suiça”. A discussão faz parte da pesquisa atual desenvolvida pela autora na UNESP de São José do Rio Preto. Acessar o artigo diretamente em: http://sare.unianhanguera.edu.br/index.php/rtcom/article / view / $151 / 150$
}

TRadTERM, 15, 2009, p. 155-171 
(caso de homônimos, parônimos e outros, cuja semelhança é resultante de mera coincidência fonética ou gráfica) são relativamente próximos - às vezes, idênticos - , ao passo que seus significados ou usos são distintos. Sem contar que há centenas de falsos cognatos e expressões ou locuções semelhantes que fazem, em cada país ou região, referências a realidades ou situações legais e jurídicas distintas.

Há um grande interesse, portanto, pelos termos cuja polissemia ultrapassa as fronteiras nacionais. Alguns dos termos analisados partem de termos cognatos - palavras de linguas diferentes cujos significantes (fônicos e/ou gráficos) respectivos são muito semelhantes, ao passo que seus significados são distintos (como no estudo de caso aqui apresentado). Assim, veremos que alguns termos giram em torno de "formas" muito semelhantes entre si, porém seus conteúdos/designações ora se aproximam, ora se distanciam, revelando possibilidades tradutórias praticamente ausentes das obras lexicográficas francesas unilingues ou bilingues (francês $><$ português), inclusive até daquelas mais especializadas como os glossários jurídicos.

\section{Sobre os termos estudados - problemática e alguns exemplos}

Os termos legais e/ou jurídicos presentes em documentos oficiais, registros e certidões civis, embora inseridos em textos sintaticamente menos complexos que os textos legislativos, têm como principal especificidade o fato de fazerem referência a sistemas legais cujas lógicas de pensamentos estão ancorados numa cultura jurídica bem particular. Os termos empregados para designar os títulos de pessoas, funções, instituições, departamentos, serviços, leis etc, podem ser muito diferentes até mesmo em países distintos que falam a mesma língua como, por exemplo, países francófonos como a França e a Suíça francesa. Isso decorre principalmente do fato de que os textos jurídicos são frequentemente o resultado de reflexões de ordem ética, filosófica, psicológica, histórico-cultural e mesmo religiosa próprias a cada país, a cada nação.

Em relação ao léxico institucional, o francês da Suíça emprega termos que se distinguem no uso do francês da França.

TRadTerm, 15, 2009, p. 155-171 
Além de certa tradição política que os justifica, uma das razões para esse fato é histórica: a língua escrita que toma o lugar do latim progressivamente desde o século XIII e a linguagem falada que substitui os dialetos franco-provençais desde o século XVII na Suiça francesa não foram normalizadas por imposições oficiais, como ocorreu na França a partir do novo Regime instalado em 1789, que aboliu muitos arcaísmos. De acordo com o Dictionnaire Suisse Romand - Particularités lexicales du français contemporain (1997), muitas expressões que envelheceram na França permaneceram vivas na Suiça francesa, e as transferências de palavras dialetais na língua francesa falada nesse país são muito numerosas. Decorre desse fato que certas singularidades regionais puderam subsistir nos textos oficiais de alguns cantões suiços enquanto as mesmas desapareceram na França.

A matéria é, portanto, abundante, rica em quantidade e em expressividade e especialmente interessante no que se refere à categoria das palavras que não têm o uso equivalente na França, como "major de table" para "chefe de cerimonial" ou "syndic" para "prefeito" (análogo ao Maire na França). Este estudo se limita à abordagem dos helvetismos, mas poderia ser, ocasionalmente, ampliado no âmbito da francofonia, incluindo os quebecismos, os belgicismos, os africanismos etc... É interessante descobrir que também na Bélgica o termo Maire tem um correspondente lexical particular, bourgmestre, mas que, diferentemente do termo syndic usado na Suiça, é acatado e tem uma entrada no dicionário, como mostra o Petit Robert eléctronique:

Bourgmestre. Premier magistrat des communes belges ( $\Rightarrow$ maïur), suisses, néerlandaises, allemandes. Le bourgmestre est l'équivalent du maire.

Além disso, esse termo tem seu correspondente em português definido com clareza e detalhamento no Dicionário Houaiss:

Bourgomestre. Primeiro magistrado municipal de certas cidades da Alemanha, Bélgica, Países Baixos e Suíça, equivalente a prefeito, no Brasil, e a presidente da Câmara, em Portugal.

TradTerm, 15, 2009, p. 155-171 
Uma hipótese a ser verificada quando se trata de documentos suiços aponta para a seguinte problemática: parece haver mais dificuldades para o tradutor brasileiro no momento da tradução do que no da versão, uma vez que se supõe que os termos empregados na França sejam também conhecidos e mesmo bem "tolerados" na Suiça, ainda que muitas vezes o uso oficial suíço adote uma forma particular. Essa ideia se fundamenta no fato de que as relações internacionais passam de preferência pela capital da Suíça (Berna), que é um dos cantões mais desenvolvidos no sentido cosmopolita e cujos textos de leis estão mais adaptados ao francês padrão da França.

Ora, o mesmo não ocorre na tradução para o português de papéis suíços que tenham sido emitidos em um dos outros cantões, como por exemplo, os históricos e diplomas escolares, ou mesmo certidões civis de casamentos, nascimentos etc... Por exemplo, não deverá haver falta de entendimento grave se o tradutor, ao verter um documento escolar para o francês cujo destino é uma escola suíça, informar que o nível do estudante em questão é o Baccalauréat, ainda que o termo mais frequentemente empregado na Suíça seja Maturité. Ou ainda quando, ao verter um título de eleitor, empregue o termo francês Carte d'électeur, ainda que o termo de uso administrativo escrito seja, na Suiça, Citoyen actif. Por outro lado, o tradutor provavelmente teria dificuldades diante de um termo suíço como Acte d'origine. Analisemos rapidamente este termo, verificando o que consta no Dictionnaire Suisse Romand Particularités lexicales du français contemporain (1997):

Acte d'origine: document officiel établissant la commune d'origine d'une personne et émis à sa demande. Délivrer un acte d'origine. Acte d'origine annulé.

Visto que o termo que nomeia esse documento remete aos termos "origine, originaire", convém explicitar ao leitor o seu amplo uso na Suíça:

Lieu, commune, village D'ORIGINE, dont on est bourgeois, où l'on jouit des droits de bourgeoisie. La commune d'origine est celle qui confère au citoyen sa nationalité, par filiation,

TRadTerm, 15, 2009, p. 155-171

TradTerm 15.pmd 159

$21 / 9 / 2010,14: 54$ 
160

mariage ou naturalisation. Ex: Veuillez inscrire sur ce formulaire votre lieu d'origine.

ORIGINAIRE: (Dr.civ.) Originaire de, dont la commune d'origine est, qui est bourgeois de, qui jouit des droits de bourgeoisie de. Ex: Cette française naturalisée suisse est originaire de Sierre, mais n'y a jamais mis les pieds; c'est la commune d'origine de son mari. M. Suter est originaire de Bâle de par son père, mais il est né en Australie.

Dois exemplos do termo, contextualizado em situações reais divulgadas pela imprensa, permitirão uma melhor verificação do significado do termo acte d'origine:

EX. 1. Pour obtenir un passeport, il faut se présenter à la préfecture $d u$ district de domicile muni des document ciaprès: [...] un acte d'origine, délivré par la commune d'où l'on est ressortissant. Cet acte doit être conforme à l'état civil actuel de la personne qui le présente (célibataire, marié, veuf ou divorcé). Feuille des avis officiels du canton de Vaud, $1^{\text {er }}$ octobre 1974 , p. 2438.

EX. 2. (métalinguistique) "Demandez à votre traducteur anglais établi chez nous depuis cinq ans à quel point il a dû se familiariser avec les particularités terminologiques suisses en politique nationale ou dans le domaine de nos institutions. A défaut de ces connaissances, le traducteur anglophone d'outre-Manche ou d'outre-mer pensera que votre "commune bourgeoise " se réfère à la lutte des classes, que les " radicaux " et les "libéraux " sont des partis du centre gauche et que votre " lieu d'origine " est l'endroit où vous êtes né " Le Nouveau Quotidien, 4 juillet 1994, p. 4.

Enfim, um detalhe muito importante que distingue as culturas francesa e brasileira em relação a essa especialidade do texto juramentado está no fato de que os documentos de registro civil são emitidos naquele país, assim como na Suiça, pela administração pública (municipal, regional, departamental ou cantonal)

TRADTERM, 15, 2009, p. 155-171 
enquanto que, no Brasil, eles são expedidos e oficializados por tabelionatos ou cartórios. Essa situação colabora para aumentar os obstáculos no estabelecimento da equivalência de muitos termos empregados nesses documentos.

\section{Um puzzle - estudo de caso}

O estudo de caso destaca o termo Syndic, que, por sua natureza polissémica, é objeto passivel de equívocos semânticos e pode se tornar uma verdadeira armadilha na tradução se o documento original tiver sido produzido em alguns cantões da Suíça francesa, onde o termo é empregado para denominar o Maire. Este último, por sua vez, tem o seu "equivalente" em português para indicar o "Prefeito", mas essa equivalência também é problemática e não corresponde à função daquele que assina os documentos de registro civil no Brasil. Quando falamos em "equivalência funcional", referimo-nos exatamente à uma equivalência de funções. Temos portanto, aqui, um problema primeiramente em nivel intralingual antes de passarmos à tradução, que traz nessa equivalência, um problema em nivel interlingual.

Como alinhar termos como Síndico e Prefeito ao lado de Syndic, Maire e Préfet? Como determinar os equivalentes - caso estes existam - na tradução/versão? Partindo do termo francês syndic, foi necessário um acesso ao material lexicográfico próprio à Suíça para descobrir que, em certos cantões na Suiça, esse termo designa outra função daquela indicada pelo termo na França, a mesma função do "síndico" no Brasil; ao mesmo tempo, descobriu-se que o termo na acepção usual em cantões da Suíça francesa é raramente abordado pelos mais tradicionais dicionários de lingua francesa. Assim, o termo syndic é empregado oficialmente para designar o "prefeito" nos cantões de Vaud e de Fribourg, assim como o composto députésyndic, funções essas que correspondem ao Maire e ao député-maire na França. E ainda, o "prefeito" é designado pelo termo président nos cantões de Valais e de Neuchâtel. Os cantões que empregam o termo Maire são os de Berna, Genebra e Jura.

A partir desse emaranhado de termos muito semelhantes na forma, as prováveis confusões nos levaram a verificar cuidadosamente o repertório dos verbetes que os definem, tanto nos dicionários

TRadTerm, 15, 2009, p. 155-171 
bilingues quando nos unilingues. Buscamos qualquer possibilidade de menção a esses termos, primeiramente nos verbetes "sindico" e "prefeito" - os dois termos imediatamente envolvidos na tradução de syndic-e, estendendo a busca em torno de Maire, indo até o termo Préfet, uma vez que este último termo surgiu como o cerne de uma grande possibilidade de confusão nas traduções, tanto por causa das definições dadas em dicionários impressos bilingues francês/português como aquelas encontradas em ferramentas de tradução ou dicionários eletrônicos. Por exemplo, no LAROUSSE da Collection Apollo de 1957 (edição 1990) a resposta para o termo préfetfoi "prefeito", e vice-versa. No GRANDE DICIONÁRIO FRANCÊS / PORTUGUESS - Domingos de Azevedo (1980), assim como no DICIONÁRIO FRANCÊS / PORTUGUÊS - Paulo Rónai (1989), a primeira tradução em português de préfet é "prefeito", sem mais explicações. O LAROUSSE DE POCHE (1996), traduz préfet por "governador". Verificamos, entretanto, que na direção do português para o francês, o termo "prefeito" é quase sempre traduzido por Maire, e tal fato acentua nossa impressão mencionada anteriormente de que a problemática na tradução parece ser mais complexa do que na versão.

Um dos fatores que agravam a situação deve-se ao fato de a maioria dos dicionários bilíngues francês $><$ português ter como referência o português de Portugal - onde o Maire, por sinal, é o Presidente da Câmara. Porém, como justificar a imprecisão no caso de um dicionário brasileiro como o de Paulo Rónai, quando traduz préfet por prefeito?

Voltemos ao termo inicial syndic e tomemos agora os seguintes trechos publicados na imprensa suíça e citados no Dictionnaire Suisse Romand (1997, p.681-682):

Mme C.P.-G. [...] est élue syndic à la place de M.J. T. [...], qui se retire après douze ans de présidence de la commune. C'est la première femme qui devient syndic dans le canton de Vaud. "Feuille d'Avis de Neuchâtel, 12 janvier, 1977, p. 9.

De fait, la syndique de Lausanne défend aujourd'hui l'idée d'une région à deux vitesses qui dans un premier temps regrouperait les communes les plus proches du chef-lieu " Journal de Genève et Gazette de Lausanne, 4 avril 1993, p. 14.

TRadTerm, 15, 2009, p. 155-171 
Suponhamos que o tradutor esteja diante de um documento oficial original da Suíça francesa e que se depare com o termo syndic ${ }^{2}$. Observamos, baseando-nos no primeiro trecho acima, que tal função remete a présidence de la commune, informação que menos esclarece do que colabora para o desvendamento da situação. Temos aqui, portanto, três termos problemáticos: syndic, présidence et commune. Um tradutor inexperiente poderia traduzir esses termos "literalmente" por: síndico, presidente/presidência, comuna e por aí adiante.

Antes de procedermos à busca desses termos nos dicionários de língua francesa e de língua portuguesa, cabe dizer que uma das preocupações inerentes a essa questão da variante regional ou nacional de uma língua interroga, primeiramente, o tradutor juramentado brasileiro: ainda que ele consiga superar a ausência de uma formação jurídica específica em sua atividade, indagamos se ele estaria sempre atento às possiveis diferenças que uma variante nacional pode ter em relação à língua padrão (no caso, o francês da França é considerado o padrão). Em segundo lugar, não se pode ignorar a falta de material disponivel e ao alcance imediato do tradutor, pois, ainda que numa hipótese otimista exista tal material especializado, nem sempre há tempo hábil para obtê-lo, uma vez que essa prática se desenvolve, muito frequentemente, em situações de prazos curtíssimos, quando não emergenciais. A Internet, hoje indispensável, não consegue ainda suprir todas as necessidades do tradutor.

A busca em obras lexicográficas realizada neste estudo mostra que os equívocos podem ser facilmente cometidos se não houver, da parte do tradutor, uma permanente inquietação diante de equi-

2 Ou syndique, visto que a feminização dos nomes de profissões é amplamente defendida na Suiça, contrariamente à resistência da Academia francesa. Embora tal medida tenha sido oficialmente divulgada na França por uma circular de 11 de março de 1986, só foi efetivamente aplicada quando, em 1998, as mulheres do governo de Jospin reivindicaram para si a feminização do título de "Ministra" da seguinte forma: "Madame la Ministre" (conf. em http://grammaire.reverso.net/ index alpha/Fiches/fiche349.htm).

TRADTERM, 15, 2009, p. 155-171 
164

valências prontamente estabelecidas nos dicionários bilingues. A situação se complica mais ainda quando tentamos determinar as equivalências "funcionais" - afinal, é disso que se trata em tradução juramentada: encontrar termos que equivalem às funções "semelhantes" em cada país. Assim, a passagem de uma língua para outra é acompanhada pelo resvalamento de uma tradição jurídica para uma outra, de modo que uma equivalência, que deveria ser precisa, na realidade só o é aproximativamente. Ou seja, paradoxalmente, a precisão exigida do tradutor juramentado depende de conceitos que são relativamente imprecisos pelo fato de estarem prisioneiros da tradição histórica e jurídica na qual se desenvolveram.

Partindo de um texto francês da França, podemos afirmar sem titubeios que o termo Maire é o equivalente funcional do termo "Prefeito" no Brasil porque, embora saibamos que as atribuições de cada um não sejam exatamente as mesmas, eles assemelhamse suficientemente pelo conteúdo que os define como "representante municipal eleito pelo povo", o que nos permite justificar a adoção do termo na tradução. Tal conclusão, porém, não resolve definitivamente o efeito de estranhamento do leitor brasileiro quando se trata da tradução de documentos, pois o fato de ser o Prefeito quem emite e assina os documentos de registros civis continuará sendo uma diferenciação cultural bem marcada. Aqui se percebe como a tradução juramentada enfrenta os percalços mais sutis: sua obrigação é ser fiel ao documento original, porém, embora todos os termos remetam à função de "oficial de registro civil", no Brasil, quem emite e assina esses atos são os tabeliães, os notários. Portanto, será que podemos simplesmente traduzir a assinatura do Maire na França, ao qual é atribuída função de "oficial de registro civil", pelo termo que designa a mesma função no Brasil e traduzir Maire por Oficial, Tabelião, Notário, ou Escrivão Substituto etc.? Da mesma forma, corre-se o risco de encontrar o seguinte resultado: um "Síndico" ou um "Presidente" — ambos na função do "Maire/ Prefeito" na qualidade de oficial civil - assinando uma certidão civil suíça, caracterizando uma estranheza ainda maior para o leitor brasileiro. A matéria é, portanto, complexa.

Vale insistir que a questão passa a ser muito delicada quando o texto original em língua francesa vem de outro país francófono que não seja a França, porque nesses documentos relativamente

TradTERm, 15, 2009, p. 155-171 
"simples", as referências a tais títulos são breves e pontuais muito frequentemente presentes apenas nos cabeçalhos, carimbos e assinaturas - e, assim, os riscos para um tradutor desavisado são enormes.

\section{Pesquisa lexicográfica dos termos em francês}

\section{Syndic}

Os resultados para a busca em dicionários do termo Syndic são as seguintes:

NOUVEAU PETIT LAROUSSE EN COULEURS

(1968, p.900): n.m. (gr. sundikos, qui assiste quelqu'un en justice). Celui qui a été désigné pour prendre soin des affaires d'un groupe de personnes, d'une compagnie ou d'une corporation. // À Paris, titre d'un des membres du bureau du conseil municipal.

Esse dicionário, mais antigo, antecipa na primeira definição do termo um sentido que, como veremos, continuará sendo aquele mais frequentemente usado, ou seja, o de "representante", ainda que, neste caso, não remeta à gestão de falências. Entretanto, na segunda acepção, o fato de remeter ao contexto "municipal" aproxima-o mais do uso suíço, embora não remeta à função específica de "Prefeito", como ocorre na Suíça.

O dicionário eletrônico PETIT ROBERT ÉLECTRONIQUE, em sua versão mais atual, define assim o termo Syndic (tomamos apenas as acepções modernas):

2) 2.1Mod. (En France) Membre du bureau du conseil municipal de Paris chargé de l'aménagement et de la surveillance des locaux réservés au conseil, de l'organisation des fêtes et des réceptions.

TradTerm, 15, 2009, p. 155-171

TradTerm 15.pmd 
$\diamond$ Syndic des gens de mer: représentant de l'Inscription maritime.

$\diamond$ Membre d'une chambre de discipline chargé de surveiller les officiers ministériels. Le syndic d'une chambre d'avoués, de notaires.

2.2 Dr. comm. Syndic de faillite: mandataire désigné par le tribunal, pour représenter les créanciers du débiteur et assister ou représenter ce dernier, notamment pour la gestion et la liquidation de ses biens (profession supprimée en 1985). $\Rightarrow$ liquidateur.

2.3 Mandataire choisi par les copropriétaires d'un immeuble pour faire exécuter les décisions de l'assemblée (cf. Administrateur de biens).

O verbete nos elucida quanto ao uso atual do termo na França. A primeira acepção, curiosamente, faz alusão a um contexto relacionado ao município, portanto, é o que mais se aproxima do uso na Suíça para o termo Maire, porém não remete explicitamente à função do Maire. A segunda acepção remete ao uso mais frequente do termo syndic - representante dos credores na liquidação dos bens do devedor. Também no Brasil, como veremos, o termo síndico é empregado na linguagem jurídica para designar essa função. Enfim, temos uma terceira acepção do termo em língua francesa, que é aquela mais conhecida popularmente como o "síndico que administra um condomínio".

Podemos conferir a seguir o verbete "síndico" de acordo com o

DICIONÁRIO AURÉLIO ELETRÔNICO.

1. Antigo procurador de uma comunidade, de cortes, etc.

2. Advogado de corporação administrativa.

3. Sindicante (2).

4. Individuo escolhido para zelar ou defender os interesses duma associação, duma classe, etc.

5. Bras. Nos edifícios em que há condomínio, pessoa escolhida pelos condôminos para tratar dos interesses e da administração do imóvel.

TradTerm, 15, 2009, p. 155-171 
6. Bras.Dir. Administrador duma falência, sob a imediata direção e superintendência do juiz, que o escolhe pela sua idoneidade moral e financeira entre os maiores credores do falido, podendo a escolha recair em pessoa estranha idônea e de boa reputação, se três credores renunciarem seguidamente à nomeação.

$=$ LIQUIDANTE $=[$ De liquidar + -nte. $]$

Consultamos em seguida um dos mais renomados dicionários jurídicos em língua francesa, o Vocabulaire Juridique (2000), de Gérard Cornu. As definições para o termo syndic, como se pode verificar abaixo, referem-se estritamente ao uso jurídico do termo, nos sentidos já indicados anteriormente:

1. Agent chargé de prendre soin des affaires de certaines personnes, compagnies ou corporations.

2. Parfois, le président de la compagnie ou de la corporation.

de faillite. Naguère, représentant légal de la masse des créanciers du failli, considéré par la loi comme représentant aussi le failli dont il gère et liquides les biens et au nom de qui il agit en justice en raison du dessaisissement dont le failli est frappé. V. représentant des créanciers.

de règlement judiciaire lou de liquidation des

biens). Naguère, mandataire de justice chargé, sous sa responsabilité, de mettre en œuvre la procédure, de représenter la masse des créanciers et de remplacer, ou d'assister le débiteur (selon que ce dernier est ou non dessaisi) dont les attributions sont aujourd'hui scindées entre le représentant des créanciers et l'administrateur judiciaire. V. aussi mandataire, liquidateur.

___ des gens de mer. Agent subalterne de l'administration de la marine marchande chargé de la gestion des stations maritimes pour la surveillance et police de la navigation.

d'une chambre de discipline. Membre d'une chambre de discipline élu pour exercer devant cette juridiction les fonctions de poursuite des fautes disciplinaires.

Constata-se que o termo é mais usado no sentido de: Représentant des créanciers d'un débiteur en faillite = Representante dos credores de um devedor em falência.

TradTerm, 15, 2009, p. 155-171 
Também o IATE, a base terminológica multilingue da UE (http:/ / iate.europa.eu/iatediff/SearchByQueryLoad.do?me thod=load) aponta na tradução do francês para o português (de Portugal) apenas para o significado jurídico do termo, assim definido: "mandatário assalariado do falido ou dos credores, encarregado das operações de uma falência".

O GRANDE DICIONÁRIO FRANCÊS / PORTUGUÊS, de Domingos de Azevedo, permanece muito próximo das definições privilegiadas pelos dicionários franceses, como o Petit Robertjá citado.

Sindico, o que é nomeado para curar dos interesses de uma comunidade, de uma corporação de que é membro. // Jur. Síndico, aquele que, nas falências, é encarregado de representar a massa dos credores. // Mar. Síndico, o protector (sic) dos marinheiros em certas localidades.

Já o DICIONÁRIO FRANCÊS-PORTUGUÊS de Paulo Rónai (1989) apresenta assim a definição de syndic:

1. síndico (representante de credores) ;

2. síndico (mandatário dos co-proprietários de um edifício).

Assim estão definidos os termos no Dictionnaire Suisse Romand (1997, p.681):

SYNDIC, SYNDIQUE $\mathbf{n} . \mathbf{m} . \mathbf{f}$.

Premier magistrat d'une commune, maire. P président ; syndicature.

"Il y a dans chaque commune une municipalité, composée d'un syndic, qui en est le président, et de conseillers municipaux, dont la loi fixe le nombre. "Constitution $d u$ Canton de Vaud, art. 86.

PRÉSIDENT, -ENTE n. m. f.

Premier magistrat (d'une ville, d'une commune). Président de commune. Le président de la ville. Un président de village. $\Rightarrow$ syndic.

TRADTERM, 15, 2009, p. 155-171 
Percebe-se aqui o comparecimento de um índice remissivo muito bem organizado, que nos faz compreender claramente as variações em torno dos dois termos e também se pode concluir, pelo artigo da Constituição do Cantão de Vaud citado acima que, na Suíça francesa, os documentos civis podem ser assinados e autenticados/legalizados por um Maire, por um Syndic ou por um Président.

O resultado parcial desta pesquisa, iniciada em torno do termo central que designa a função do syndic na Suiça, é bastante esclarecedor, pois aponta para uma ausência significativa, nos dicionários bilingues ou unilíngues de língua francesa, de registro da acepção do termo que remete precisamente à função do termo correspondente na França, a de Maire (Prefeito). Mais ainda: não há registro de ocorrência do uso jurídico de "liquidante" para o termo syndic na Suíça, nem do uso mais popularmente conhecido de "administrador de bens ou de condomínio".

A pesquisa passará a buscar os termos Maire, Préfete ainda verificar o que acontece na direção inversa, do português para o francês, para o termo Prefeito. Veremos que essa análise corrobora a constatação de que o uso do termo na Suiça francesa não é registrado pelos dicionários em geral. Devido à impossibilidade de relatar neste artigo a íntegra dos resultados de todos os termos envolvidos, limitamo-nos à apresentação dos resultados para o termo Maire, considerado aqui como o "equivalente" usado na França do termo suíço Syndic, destacando aqui, assim, apenas os dois termos centrais do estudo de caso.

\section{Maire}

PETIT ROBERT ELECTRONIQUE

1) $(\mathrm{XII})$ Hist. Celui qui dirigeait le corps municipal d'une commune jurée ou "ville de commune ".

2) (1789) En France, Premier officier municipal élu par le conseil municipal, parmi ses membres, et qui est à la fois une autorité locale et l'agent du pouvoir central. $\Rightarrow$ bourgmestre, maïeur. Le maire, premier magistrat de la

TradTerm, 15, 2009, p. 155-171 
commune. Monsieur, Madame le maire ( $\Rightarrow$ mairesse). Le maire et ses administrés. L'écharpe du maire. Adjoint au maire. - Le maire de Paris. Les maires d'arrondissement.

O GRANDE DICIONÁRIO FRANCÊS / PORTUGUÊS de Domingos de Azevedo segue uma definição empregada em Portugal, mas estranha e confusa para o tradutor brasileiro (não menciona a palavra "Prefeito"):

MAIRE. Presidente das câmaras municipais em França (excepto em Paris). / / Maire du palais, mordomo-mor do rei.

Já o Dicionário Francês-Português de PAULO RÓNAI (1989) apresenta assim a definição de Maire:

MAIRE. Prefeito; (em Paris, aprox) administrador regional.

A menção a uma tradução "aproximada" de "administrador regional" quando se trata da cidade de Paris não se justifica, pois não esclarece que, ainda que o Maire da capital francesa tenha uma função mais abrangente e complexa do que os prefeitos de outras cidades, a tradução do termo continua sendo "exatamente" Prefeito, em lingua portuguesa. Diremos "o Prefeito de Paris" assim como "o Prefeito de Marselha".

O IATE também só menciona a tradução de Maire para o termo empregado em Portugal, definido como o "Presidente da Câmara".

\section{Comentários finais}

Conclui-se, até o momento, que nenhuma obra lexicográfica consultada relaciona explicitamente o termo Syndic ao seu correlato Maire. A explicação histórica do uso do termo Syndic na Suíça remeteria ao "suserano" ou "senhor feudal" da cidade, e que permanece na França como título do membro do conselho municipal encarregado da vigilância dos locais. Essa ideia de "vigilância dos locais" remete ao atual significado do termo para "síndico".

Esta pesquisa revela que na tradução juramentada, os termos relativos a nomes de profissões devem receber uma atenção

TRadTERM, 15, 2009, p. 155-171 
especial da parte do tradutor. Outros termos repertoriados e posteriormente estudados, também passiveis de dificuldades, dizem respeito aos nomes de documentos, como por exemplo "antecedentes criminais" para traduzir um "casier judiciaire". Será que um tradutor pode afirmar e conseguirá facilmente confirmar se na Suíça o termo usado é o mesmo que na França? Um "acte d'origine", que é documento inexistente na França, seria traduzido como para o português?

Consideramos de grande importância todos os esforços na direção de uma ampliação dos recursos e ferramentas destinados ao trabalho de grande responsabilidade dos tradutores juramentados, cuja profissão está submetida, no Brasil, às normas e leis das Juntas Comerciais.

\section{Referências bibliográficas}

AZEVEDO D. (1980) Grande Dicionário Francês / Português. Lisboa: Livraria Bertrand

CORNU G. (2000) Vocabulaire Juridique. France: Quadrige / Presses Universitaires de France.

FERREIRA A.B.H. (1980) Médio Dicionário Aurélio. Rio de Janeiro: Nova Fronteira.

HOUAISS Dicionário Eletrônico

IATE (http://iate.europa.eu/iatediff/SearchByQueryLoad.do?method=load) LAROUSSE Collection Apollo de 1957 (edição 1990), Paris, Larousse.

LAROUSSE DE POCHE Français-Portugais, Portugais-Français (1996), Paris, Larousse.

LE PETIT ROBERT ÉLECTRONIQUE

PETIT LAROUSSE ILLUSTRÉ (1991) Paris: Librairie Larousse.

RONAI P. (1989) DICIONÁRIO FRANCÊS / PORTUGUÊS. Rio de Janeiro: Nova Fronteira.

THIBAULT, A. (1997) Dictionnaire Suisse Romand: Particularités lexicales du français contemporain. Genève: Éditions Zoé.

TRadTerm, 15, 2009, p. 155-171

TradTerm 15.pmd 